\title{
Application and Development of Intelligent Manufacturing Equipment in Fashion Design Jing $\operatorname{Han}^{1}$, \\ 'Jilin Engineering Normal University, Changchun City, Jilin Province, China, 130000
}

\begin{abstract}
Keywords: Intelligent manufacturing equipment; Fashion design; Application and development
\end{abstract}
\begin{abstract}
Intelligent manufacturing was proposed in many Western countries as early as in the 1980s. With the development and improvement of the information technology, the speed of intelligent manufacturing in China has been significantly improved. Intelligent manufacturing has been applied extensively in various industries and is playing an increasingly prominent role. Fashion design is a kind of art in this field as well as a form of art with the perfect combination of art and application. Fashion design is actually a solution to solving the dressing issue in people's life and a creative performance of the creative behavior. Based on the concept of intelligent manufacturing and some characteristics of intelligent manufacturing, this paper analyzes the current situation and the application of intelligent manufacturing equipment in garment design and analyzes the advantages and functions of intelligent manufacturing equipment in the fashion design to provide a prospect for the application and development of intelligent manufacturing equipment in fashion design. It is believed that the application of intelligent manufacturing equipment in fashion design can provide more intelligent and precise service for garment design and improve the efficiency of design and design effect.
\end{abstract}

\section{Introduction}

The progress and development of the information technology has greatly changed people's life and work. The information technology has been widely applied to the development and utility of the information network technology, intelligent manufacturing technology, new energy and new materials, etc. The upcoming of a new round of technological innovation has had a very profound impact on the development of various industries and played a very good role of promoting their development. Ever since the reform and opening up, the Chinese society has been developing rapidly, and prominent achievements have been made. Intelligent manufacturing equipment highlights the feature of being intelligent, which substantially improves the production efficiency and is conducive to promoting the rapid development of the industry. As a comprehensive combination of many meta, three-dimensional and time elements, fashion design has become an important behavior for people to meet the needs of clothing and dressing psychology. In the whole design process, the clothing design highlights the comprehensiveness and the wide range of features. It is a whole process of planning for human clothing. To apply intelligent manufacturing equipment in the fashion design can help to accurately grasp the design process, give full play to the artificial intelligence's function of the intelligent manufacturing equipment, help people to complete the design process, effectively improve the design efficiency. Besides, it can give designers a broad design space so that the design effect can be perfectly demonstrated through the intelligent equipment, thus promoting the progress and development of the fashion design industry. Therefore, it has a broad application prospect.

\section{Introduction to Intelligent Manufacturing}

In terms of concept, intelligent manufacturing is not the traditional sense of the manufacturing process, but it is a "big manufacturing" concept. Intelligent manufacturing incudes the design, organization, supply, sales, retirement, recycling and other various activities throughout the product's entire life cycle. According to the implied meaning, intelligent manufacturing consists of two parts, namely, intelligent manufacturing technology and intelligent manufacturing system.

Intelligent manufacturing technology mainly refers to the manufacturing technology, systems 
engineering, automation technology and artificial intelligence technology integrated in the equipment manufacturing process. The staggered application of a number of core technologies form a comprehensive and strong technology. Intelligent manufacturing system refers to the specific work environment for the integration and application of the intelligent technologies. Intelligent manufacturing system is also the carrier for the realization of intelligent manufacturing equipment's manufacturing model. Intelligent manufacturing system is composed of intelligent robot and human experts together to constitute a man-machine integration system. In this system, a highly flexible and integrated approach can be demonstrated in every aspect of the manufacturing process to achieve the simulation of human intelligence activities through the computer, and replace or extend the manufacturing process of human mental work through analysis, judgment, reasoning, ideas and decision-making. And in this way, intelligent manufacturing equipment's information collection, storage, improvement, sharing, inheritance and development can be achieved so that the machine will have the "brain" of human experts and complete the specific work according to the expert's thinking and behaviors.

Throughout the manufacturing process, this manufacturing model highlights the value and status of knowledge in the entire manufacturing activities, and the main economic situation after the industrial economy is the knowledge economy, which fully demonstrates the huge development potential of the intelligent manufacturing in the knowledge economy. The Intelligent manufacturing will become an advanced manufacturing mode of production in the future economic development, greatly promoting the development of knowledge-based economy.

\section{Features of Intelligent Manufacturing Equipment}

Intelligent manufacturing is gradually developed through artificial intelligence research. In general, intelligence is the sum of knowledge and intelligence and the basis of function while intelligence is the ability to acquire and apply knowledge to find answers. Intelligent manufacturing equipment is the comprehensive manufacturing equipment with both this knowledge and intelligence. Its main features include the following aspects:

\section{Achieve Man-Machine Integration}

Intelligent manufacturing equipment is not a simple artificial intelligence system, but an intelligent system with the realization of the human-machine integration. Such intelligent manufacturing equipment can not only show logical thinking and image thinking, but also has inspiration. Intelligent manufacturing equipment can independently complete the analysis, judgment and decision-making tasks. The intelligent system with man-machine integration can fully play the potential of people with the cooperation of machinery and equipment, and then to achieve equality between man-machine work, mutual understanding and mutual cooperation relationship.

\section{Reflect the Virtual Reality Technology}

Virtual reality technology is based on the computer and integrated with signal processing, animation technology, intelligent reasoning, prediction and multimedia. Besides, a variety of images and sensors are used to virtually reflect the various processes and parts in real life and simulate the manufacturing process and future products. The virtual reality technology is one of the key technologies to realize the high level of man-machine integration.

\section{With Self-Organization and Hyper-Financial Capacity}

In the self-organization and hyper-integration in the intelligent manufacturing system, the various components can be achieved according to the needs of the task and the ability to form a structure. The melting of the device is not only expressed in the mode of operation, but also in the form of structure, so this melting is called hyper-capping. This means that the device is like a group of human experts, like the group, not only with biological characteristics, but also with self-organizing ability.

\section{Have Self-Study and Self-Maintenance Ability}

Intelligent manufacturing equipment in practice can continue to enrich the knowledge base, and 
have a certain self-learning ability. It can achieve the process of running the fault of self-diagnosis to achieve self-exclusion and self-recovery and finally protect the normal operation of equipment.

\section{With Self-Discipline}

An intelligent device has the ability to self-discipline, and its self-perceived ability is the foundation. The device senses and understands the environmental information and the device's own information through the perceptual system, and realizes the planning of self-behavior and ability through analysis and judgment. This self-perceived device is called intelligent equipment, intelligent machines to a certain extent, the performance of independence, personality or mutual coordination, movement, competition and other characteristics, so that the machine has the ability to self-discipline. In addition, the device is self-disciplined on the basis of a model that can perceive changes in the environment and make adjustments to their behavior by analyzing the ability to support them with strong support and memory support.

\section{Current Status of Fashion Design}

As a behavior completed through fashion concept, fashion design covers a wide range of aspects, is strongly comprehensive and reflects the overall planning process. At present, China's fashion industry is faced with the intensified industrial restructuring. The upgrading of the fashion market directly reduces the supply quantity and requirements. Market competition is becoming increasingly fierce. Market segmentation and the arrival of the brand era of China's fashion design industry is facing the following status quo:

First of all, there is something wrong with the positioning of China's fashion design industry and the international market, which is specifically manifested in that the bargaining power and the processing capacity do not match, scientific innovation and product production capacity do not match, processing quantity and brand quantity do not match, the status of export channel and the global export proportion do not match, and the national influence and the industrial scale do not match.

Secondly, there is a huge loss of talents in the fashion design industry. China's fashion design industry started relatively late with slow development speed. Besides, the Chinese do not have a comprehensive understanding of the fashion design industry, leading to a huge loss of talents in the fashion design industry, which directly weakens the entire brand innovation and the scientific innovation ability of China's fashion design industry and leads to the slow development of China's fashion design industry.

Finally, the investment of human resources in China's fashion industry is small. These factors directly result in the current scarcity of professional talents and human resources. Besides, the consciousness of designers is generally backward, and managers also have relatively low quality, lack long-term strategic vision, so they cannot promote development of the industry.

\section{The Application of Intelligent Manufacturing Equipment in Fashion Design}

Intelligent manufacturing equipment can well integrate a variety of high-tech technologies to build large-scale manufacturing machinery with more powerful logical analysis capability, thinking ability, perception and decision-making capacity. Intelligent manufacturing equipment not only reflects the advantages of artificial intelligence, but also builds up a new chapter in the development of intelligent manufacturing industry. The intelligent manufacturing equipment used in fashion design can effectively improve the current stage of the apparel design industry and promote the reform and development of the industry.

\section{Effectively Improve the Designer's Work Efficiency}

As a new manufacturing model based on a new generation of information and communication technology, intelligent manufacturing relies on a strong information technology and high-tech technology to effectively improve the efficiency of new product research and development, greatly 
shorten the product development cycle and effectively improve production efficiency and product quality. Fashion design is in need for a large number of product case design and comprehensive thinking to complete a variety of ideas. Based on the application of intelligent manufacturing equipment, the fashion designer can upgrade the design efficiency. The intelligent manufacturing equipment with strong intelligence capabilities is used to continue the designer's design concept, effectively reduce the cost of fashion designers' work. Besides, through the application of intelligent manufacturing equipment, some cutting work with higher requirements for repeatability or technology can be completed relying on the intelligent manufacturing equipment, thus greatly enhancing the accuracy and efficiency of cutting. Designers are also able to reduce their time spent on technical work through smart manufacturing equipment and gain more time to find creative inspiration, which is beneficial for better design cases.

\section{Promote the Rapid Development of the Fashion Design Industry and Related Industries}

There is still a gap between the development of China's fashion industry and that of the Western developed countries, but the emergence of intelligent manufacturing equipment greatly improves the industry's productivity and production efficiency. The intelligent manufacturing equipment demonstrates powerful productivity, which fully reflect the development concept that science and technology constitute a primary productive force. Intelligent manufacturing equipment is a huge production system based on high-tech with the integration of various intelligent functions. The integration of various technologies and the application of intelligent technologies have achieved the intelligent production in the application of equipment, which has greatly improved the current production in the design industry. To ban the manual fashion production and manufacturing with intelligent manufacturing equipment can improve the efficiency and effectively improve the product quality. Besides, the intelligent manufacturing system can timely analyze the production activities, improve deficiency in the manufacturing activities and improve the production efficiency. The application of the intelligent manufacturing equipment can effectively promote the development of the fashion industry and well promote the development of relevant industries.

\section{Effectively Promote the Improvement of Professional Talents' Ability}

Intelligent manufacturing equipment is based on modern information technology and high-tech manufacturing equipment integrating a variety of intelligent technologies. To achieve the operation of these intelligent manufacturing equipment, in addition mastering professional knowledge of fashion design, it is also necessary to master the high-tech knowledge involved in the intelligent manufacturing equipment. Only by using and operating the intelligent manufacturing equipment and clarifying each detail in the equipment operation can the designer apply these details in fashion design and give the full play to the equipment's powerful intelligent advantage so as to complete the work. Therefore, fashion designers should actively learn and master technologies related to intelligent manufacturing and apply them. Thus, the application of intelligent manufacturing equipment can affectively promote the improvement of fashion designer's personal ability.

\section{The Development Prospect of Intelligent Manufacturing Equipment in Fashion Design}

Intelligent manufacturing is a combination of information technology and industrial technology integration. The emergence of intelligent manufacturing equipment provides a strong technical capacity support for the development of manufacturing and can effectively promote the development of the manufacturing industry. In terms of fashion design, the application of intelligent manufacturing equipment can effectively relieve the dilemma of the current development of the fashion design industry and promote the development of the manufacturing industry. In the future development of the manufacturing industry, intelligent manufacturing will inevitably form a new system to promote the development of the manufacturing industry and change the manufacturing methods, services and corporate organizational structure. China's fashion industry's intelligent direction is not limited to the progress of science and technology, but to explore changes in consumer demand. In the future, the fashion design major will definitely develop towards being 
intelligent and gradually form the industrial spirit with the thinking and behavioral mode of pursuing excellence in products and the market.

\section{Conclusion}

To sum up, in the innovation and development of this industrial revolution, intelligent manufacturing has effectively promoted the reform of the production mode in the manufacturing industry, realized innovation of the global supply chain management mode, effectively promoted the manufacturing industry to transform towards the service direction and effectively speeded up the transformation of cost in the manufacturing industry. The emergence of intelligent manufacturing equipment realizes the improvement of the productivity and production efficiency and effectively promoted the development of the manufacturing industry. It is an evitable choice in the development of modern science and technology to apply intelligent manufacturing in fashion design. The application of intelligent manufacturing equipment can innovate the fashion designers' design methods, design thinking and work efficiency and effectively improve the efficiency of design work. Meanwhile, the application of intelligent equipment can reduce the designers' attention to technical work, is more conducive to providing designers with more time to seek design inspiration and improve their design level so as to promote the development of the fashion design industry.

\section{Acknowledgements}

Fund Project: Jilin Province Department of Education "Double Ten" Cultivation Project "Advanced Manufacturing Technology in the Design of Clothing Accessories and Personalized Product Development".

Fund number: 2014409

\section{References}

[1] Yang Qingguang. Start from Manufacturing from here - 2016 China Intelligent Manufacturing Technology and Industry Development Summit Forum was held Smoothly [J]. Application of Electronic Technology. 2016, 42(12):3-3.

[2] Zhou Ji. Intelligent Manufacturing- Main Direction of "Made-in-China 2025" [J]. China Mechanical Engineering. 2015, 26 (17): 2273-2284.

[3] Li Yuan. Reflections on the Innovation of Costume Design [J]. Intelligence, 2017(20)

[4] Yi Lili, The Intimate Design of Intelligent Clothing and Its Development Potential Analysis [J]. Wool Spinning Technology, 2016(03)

[5] Wang Ying, Leng Dan. Existing Problems and Development of Intelligent Manufacturing Equipment Industry in China [J]. Review of Economy. 2015 (1):72-76.

[6] Lv Tie, Han Na. Intelligent Manufacturing: Global Trends and China's Strategy [J]. People's Forum • Academic Frontier. 2015 (11) :4-17.

[7] Zhang Shu. Industrial 4.0 and Smart Manufacturing [J]. Mechanical Design and Manufacturing Engineering. 2014(08):1-5.

[8] Zhu Jianying. The Meaning, Technology and Realization of Intelligent Manufacturing [J]. Machinery Manufacturing and Automation. 2013,443(23):30-35.

[9] Zuo Jian. Intelligent Fashion: Expectation in 2016 [J]. Chinese Fiber Inspection.2015(22).

[10] Tian Miao, Li Jun. The Design Pattern and Development Trend of Intelligent Clothing [J]. Journal of Textile Science, 2014, 35(02):109-115. 